\title{
LEXEMAS E CONSTRUÇÃO: ATRAÇÃO, COERÇÃO E VARIAÇÃO ${ }^{1}$
}

\author{
Marcos Luiz Wiedemer (UERJ) \\ Marcia dos Santos Machado Vieira (UFRJ)
}

Resumo: Sob orientação funcional-construcionista ou socioconstrucionista, desenvolvemos nossa reflexão sobre a temática da correlação entre lexemas e construção em prol de discutir objetos observacionais e questões teórico-metodológicas referentes aos fenômenos da atração e da variação implicados nessa compatibilização. Além do exame de preferências e restrições associadas a slots de construções, interessa-nos a análise da relação de similaridade entre as possibilidades de preenchimento, bem como a frequência/produtividade de compatibilização de um lexema em um slot de uma dada construção em relação aos lexemas que se associam a outro slot diferente da mesma construção. Em outras palavras, importa salientar a necessidade da observação de que palavras são fortemente atraídas ou repelidas por slots em uma construção (ou seja, ocorrem com mais frequência ou com menos frequência do que o esperado) e do grau de similaridade funcional entre elas.

Palavras-chave: Gramática de Construções; (Co)lexemas e Construções; Variação.

Abstract: Under Functional-Constructionist or Socioconstructionist orientation, we developed our reflection on the thematic of the correlation between lexemes and construction in order to discuss observational objects and theoretical-methodological questions referring to the phenomena of attraction and variation implied in this compatibilization. In addition to the exam of preferences and constraints associated with construction slots, we are interested in analyzing the similarity relation between the possibilities of filling, as well as the frequency/productivity of a lexeme's compatibilization in a slot of a given construction in relation

1 Título em inglês: "Lexemes and construction: atraction, coercion and variation" 
to the lexemes which are associated with a different slot of the same construction. In other words, it is important to note that words are strongly attracted or repelled by slots in a construction (that is, they occur more frequently or less frequently than what is expected) and the degree of functional similarity between them.

Keywords: Constructional Grammar; (Co)lexemes and Constructions; Variation.

\section{PREÂMBULO}

Há algum tempo temos canalizado esforços no sentido de propor uma agenda de trabalho científico que inclua a temática da variação entre as preocupações dos que se voltam para a investigação e detecção da Gramática de Construções do Português. Com isso, já tivemos oportunidades de propor problemas conceituais e problemas de heurística teóricometodológica relativos à temática a serem enfrentados numa agenda científica que se comprometa em apreciar tal temática (MACHADO VIEIRA, 2016), bem como de cogitar a pesquisa da variação na interface Sociolinguística e Gramática das Construções, com ênfase no desenho do envelope da variação, quando, então, recorremos aos conceitos de variação por allostructions (aloconstruções) e metaconstrução da literatura linguística corrente a fim de lidar com o escopo linguístico em que se podem explorar, sociocomunicativamente, constructos/usos licenciados por padrões construcionais gramaticais (relativamente) 
independentes, mas comparáveis e alinháveis por relação de similaridade configuracional (WIEDEMER \& MACHADO VIEIRA, 2018).

Neste artigo, procuramos, ao lidar com a centralidade da variação na Gramática de Construções, problematizar um lado dessa temática que, até onde se sabe, ainda carece de desenvolvimento, pelo menos entre os estudos de cunho (funcional-construcionista) realizados no Brasil, qual seja: o estatuto de formas que se compatibilizam no slot de uma construção por força de relação de similaridade/analogia entre as possibilidades de preenchimento ou por força de coerção ${ }^{2}$. No primeiro caso, entram em jogo a co-variação de colexemas (collexemes ${ }^{3}$ ) e a força de atração ou repulsa destes em relação a um slot construcional ou de um slot construcional em combinação com outro(s) por conta de propriedades formais e/ou funcionais partilhadas entre as possibilidades de preenchimento do slot na construção e as restrições deste. No segundo caso, emerge a co-variação de

\footnotetext{
2 'For example, if a phrase 'a <unknown> mouse' is received as input, a flexible match would be able to impose that the <unknown> word is an adjective based on a flexible match of the adjectival-nominal construction. This is also the way in which coercion can be modeled, such as of sentences like Adele sneezed the napkin off the table in which an intransitive verb is coerced to become a verb expressing a caused motion because the pattern of the Caused Motion construction (as in Adele pushed the book off the table) has been used here. Coercion is achieved by imposing the application of a construction even though not all its criteria are satisfied, in the example the need for a transitive verb is overruled so that the Caused Motion construction can apply." (STEELS, 2013, p.167)
}

3 Palavras que são atraídas para uma construção particular são referidas como colexemas dessa construção. (STEFANOWITSCH \& GRIES, 2003, p.214-215). 
lexemas por força de atuação da construção sobre as formas que são usadas para preenchimento de slot(s) construcionais. Neste, as formas assumem certa configuração formal e/ou funcional por força de imposições advindas da construção. Em razão disso, optamos por referir, aqui, tais formas por "(co)lexemas", a fim de representar a viabilidade de compatibilização de colexemas e lexemas num slot de uma construção. Essa forma de nomear as formas em co-variação num slot construcional visa a sinalizar o fato de entrarem em jogo: (i) de partida, formas mais similares/colexemas, ou seja, alternativas atraídas pelo slot e, portanto, mais esperadas por conta das condições de preenchimento advindas de um slot construcional e, naturalmente, por força de inclinações de uso numa comunidade; e, ainda, potencialmente (ii) formas menos alinhadas àquelas condições e, portanto, raramente ou menos atraídas pelo slot/lexemas, mas que, por força do uso (mais ou menos esporádico), são associadas ao slot construcional, e, então, por força de coerção advinda da construção, são alinhadas às mais produtivamente implicadas em tal slot. A título de exemplificação, pode-se supor que, na atualização de uma construção de movimento causado ( $X$ causa Y a mover Z) tal como "Eu [ ] slot para verbo de movimento causado a farofa para fora do prato", verbos como mover, empurrar ou jogar sejam, entre outros, candidatos mais prováveis, 
ainda que, em lugar deles, se possa ter um menos propenso a figurar nesse tipo de configuração de predicação verbal (espirrar ou tossir, por exemplo).

Entendemos, também como Hilpert (2014), que palavras possam ser mais ou menos significativamente associadas a uma construção gramatical. Com base nesse tipo de entendimento, objetivamos, em linhas gerais, explorar exemplos de atualização de certos padrões construcionais do Português e, por conseguinte, evidenciar que os (co) lexemas têm estatuto similar ao de variantes de uma variável dependente/um slot construcional, que conta com restrições/ condicionamentos de preenchimento (alguns dos quais até advindos da combinação com outro(s) slot(s) da mesma construção). Para tal finalidade, mencionaremos resultados de pesquisas que, por um lado, revelem diferenças sutis, mas sistemáticas, na configuração de significado a partir da compatibilização de certos colexemas em construções, mas, por outro, também sinalizem espaços de variação, em que se alinham, sistematicamente ou por coerção, lexemas na configuração de significado nessa compatibilização.

E, para ilustrar tais potencialidades do problema relativo ao fenômeno de variação o qual pretendemos enfrentar, neste momento, mais metateórica e metodologicamente, recorreremos à descrição de fenômenos morfossintáticos 
que revelem a existência de variantes em Português e que, por conseguinte, operem no sentido de nos ajudarem a defender que a variação pode ter lugar central numa pesquisa (funcional-)construcionista e, então, no sentido de propiciar subsídios para a consolidação da ideia de que o processo de variação, inerente a qualquer língua, também precisa ganhar relevo entre as generalizações com base nas quais se configura a Gramática Construcional do Português.

De modo a atender esse nosso anseio, configuramos o artigo da seguinte forma: na primeira seção após esta, introduziremos os alicerces teóricos e conceitos da perspectiva científica com que propomos uma reflexão sobre a temática; em seguida, explicaremos o que entendemos pela relação entre lexemas e construção; depois, exploraremos as potencialidades teóricas e metodológicas de trabalho no que diz respeito à relação entre formas linguísticas e construções, procurando, na medida do possível, exemplificá-las com base em pesquisas brasileiras sobre construções gramaticais; então, passaremos a focalizar três aspectos morfossintáticos a título de ilustrar, mais substancialmente, alternativas de trabalho, sem, com isso, enveredar, pelo menos neste artigo, no aprofundamento estatístico que as proposições de trabalho com variações aqui delineadas requerem; por fim, teceremos destaques e considerações gerais. 


\section{INTRODUÇÃO AO NOSSO OLHAR: O PRISMA TEÓRICO DA GRAMÁTICA DE CONSTRUÇÕES}

Gramática de Construções de uma língua é uma rede de padrões construcionais interconectados por alguns tipos de relações. A unidade mínima de análise é a construção, unidade simbólica em que são pareados forma (fonético-fonológica, morfossintática, lexical) e significado/função (semântica, discursiva, pragmática, social e cognitiva). O sistema linguístico configura-se, então, com base em: nós (padrões construcionais com variados graus de esquematicidade/ abstração que, em linhas gerais, constituem os recursos linguísticos e os modos de organização destes para a materialização de propósitos expressivos e comunicativos) e links entre esses nós (links de herança e links relacionais de polissemia, extensão metafórica, subparte e instanciação) ${ }^{4}$.

Assim, lidamos, essencialmente, com a ideia de que a organização da língua é idealizada por esquemas abstratos, ou seja, construções, que estão associados em uma rede construcional. Para percebermos essa organização, basta verificarmos que muitas vezes os usuários da língua dispõem, no seu repertório da língua, de construções esquemáticas, que ditam grande parte do seu conteúdo lexical, enquanto preenchem slots com novos conteúdos lexicais (conforme

4 Conforme Traugott e Trousdale (2013, p.59-62). 
exemplo citado na seção anterior). Por exemplo, "um verbo só será aceitável dentro de uma dada construção se seus argumentos forem compatíveis com os papéis especificados pela construção; isto é referido como o Princípio da Coerência Semântica" ${ }^{5}$ (GOLDBERG, 1995, p.50). Na verdade, em geral são dois os princípios que operam na correspondência/fusão entre papéis participantes de um predicador verbal e papéis argumentais de uma construção: o Princípio de Coerência Semântica e o Princípio de Correspondência (GOLDBERG, 1995 e 2006).

O primeiro - que, por sua vez, advém do entendimento de que construções de estrutura argumental são adquiridas e estocadas na memória mediante um processo de generalização pautado sobre a semântica de instâncias de um padrão empregadas com verbos particulares - assegura o imperativo de compatibilização semântica entre o papel participante oriundo do predicador verbal e o papel argumental da construção: um papel participante mais específico tem de ser "construível" como uma instância de um papel argumental mais geral. Processos de categorização operam nesse sentido. O segundo - que, por outro lado, decorre da intuição de que semântica lexical e proeminência discursivo-pragmática

5 Cf. original: la verb will only be acceptable within a given construction if its arguments are compatible with the roles specified by the construction; this is referred to as the Semantic Coherence Principle". 
normalmente se alinhem ${ }^{6}$ - assegura uma relação, em certa medida, icônica entre papéis participantes e papéis argumentais: os papéis participantes perfilados de um predicador verbal (relevantes/centrais ao estado de coisas que o predicador exprime) têm de ser codificados por meio dos papéis argumentais que a construção perfila ${ }^{7}$. Este princípio não impede (já que pode ser sobrepujado por força de algumas construções) que algum papel participante venha a ser representado por um papel argumental não-perfilado (neste caso, com função de oblíquo; como em "O enfermeiro conduziu o paciente da UTI para o quarto..$\left.^{8 \prime}\right)$, que um papel argumental se manifeste ainda que não seja perfilado pelo predicador verbal (como em "Eu espirrei a farofa para fora do prato.") ou que um papel argumental tenha sua proeminência discursivo-pragmática obliterada e, consequentemente, nem seja expresso. Este é um caso que frequentemente se nota na comparação de dados das construções ativa e passiva que viabilizam perspectivar uma predicação verbal (di) transitiva: em estruturas passivas, um papel perfilado (agente, experienciador) pode ser opcionalmente suprimido.

6 Cf. original: "That is, the participants that are highly relevant to a verb's meaning (the profiled participant roles) are likely to be the ones that are relevant or important to the discourse, since this particular verb was chosen from among other lexical alternatives" (GOLDBERG, 2006, p.40).

7 E, no perfilamento de papéis argumentais, opera-se com posições discursivamente proeminentes (que geralmente são consideradas nucleares à estrutura e se atualizam com função sintática de sujeito ou objeto, se em estruturas transitivas).

8 Construção de movimento causado: $X$ causar $Y$ a mover $Z$. 
Assim, em alguma medida, por conta da relevância sociodiscursiva e/ou pragmática de uma certa configuração de estado de coisas/papéis participantes que interessa ao falante/enunciador iluminar/perspectivar, aciona-se, mais produtivamente, um predicador verbal que a propicie em vez de outras formas alternativas em potencial de o fazer. Não é à toa que Diessel (2015, p.15-16), ao tratar da relação de lexemas e construções entre os quais defende links associativos e links probabilísticos, menciona que: verbos como give e tell são proporcionalmente mais frequentes na construção (di)transitiva (que representa uma cena de transferência), ao passo que bring e take são mais frequentes na construção to-dative (que, ainda que também represente transferência, o faz implicando alguma distância entre o agente e o alvo); não obstante, os quatro (e outros - donate, teach, send, show, offer etc.) podem compatibilizar-se com ambas, e bring é mais fortemente atraído pela construção to-dative, observando-se as experiências de uso, assim como give é mais fortemente atraído pela construção (di)transitiva.

Há, portanto, uma tendência para que as formas lexicais sejam semanticamente compatíveis como o significado construcional, mas a compatibilização semântica não é o único fator que influencia a relação entre lexemas e construções. Outro fator é, sem dúvida, sua frequência 
de uso/seu entrincheiramento na memória. Sobre isso, Diessel (2015) esclarece que:

As associações entre os verbos e construções não são totalmente previsíveis a partir de critérios semânticos. Além do ajuste semântico, é a experiência do usuário da língua com o padrão estabelecido que influencia os links associativos entre lexemas e construções. ${ }^{9}$ (DIESSEL, 2015, p.16)

Com isso, contamos, ainda, com uma propriedade do lexema: seu "perfil construcional" (constructional profile). E por perfil construcional entendemos a frequência relativa de construções em que determinado lexema aparece (um lexema pode aparecer nas construções $C_{1} \ldots C_{n}$ ), ou seja, a distribuição de construções associadas com certos lexemas.

Outra premissa do modelo baseado no uso é a de que a experiência com a linguagem cria e impacta as representações cognitivas da linguagem (LANGACKER, 1987), e essas representações são codificadas e categorizadas com base na forma fonética, no significado e no contexto (BYBEE, 2013). Desse modo, o que caracteriza a linguagem humana é o fato de unidades linguísticas individuais e sequências de unidades linguísticas se sujeitarem à repetição, processo que,

9 Cf. original: the associations between verbs and constructions are not fully predictable from semantic criteria. In addition to the semantic fit, it is the languague user's experience with the established pattern that influences the associative links between lexemes and constructions. 
por sua vez, pode levar à convencionalização delas mediante esquemas construcionais, que, nesse prisma, fazem parte da organização gramatical de um sistema linguístico.

Integra, então, nosso conhecimento linguístico um inventário de padrões construcionais gramaticais/ procedurais e padrões construcionais lexicais/de conteúdo - unidades de forma e significado/função convencionais, cognitivamente rotinizadas e, então, estocadas em nossa memória - para viabilizar nossos propósitos sociocomunicativos de conceptualização e expressão no mundo. Tais unidades lexicais e estruturais são consideradas igualmente significativas na configuração da língua, uma vez que a abordagem construcional, com orientação funcionalcognitiva, não sustenta uma separação entre as categorias lexicais e gramaticais (lexical vs. gramatical) no sistema linguístico como aludido em várias correntes funcionalistas, pois tais unidades simbólicas são concebidas a partir de protótipos formais e funcionais, em que apresentam pontos focais específicos ao longo de um continuum de "categorialidade". Assim, as representações, armazenadas na forma de exemplares, são uma resposta ao uso, ou seja, são esquemas fixados no uso. Desta feita, os padrões de usos (esquemas/subesquemas) são importantes, pois permitem ao analista da língua compreender como as categorias 
são formadas em slots esquemáticos na construção. Esses padrões construcionais (procedurais/gramaticais ou lexicais) emergem da experiência dos usuários de uma língua e resultam, consequentemente, de convencionalização definida sociohistórica, pragmática e culturalmente. Estão estocados na memória: alguns são mais produtivos, outros são menos. São, então, acionados sistematicamente nas atividades de produção e percepção/compreensão linguísticas.

Fried (2015) esclarece que alguns teóricos da Gramática de Construções até adotam os termos tradicionais lexical e gramatical como referência didática para indicar os pontos de extremidade do continuum sem perder de vista a associação entre léxico e gramática, em que se pauta esse prisma teórico. Então, se, por um lado, de início fica clara uma concepção teórica relevante à reflexão desenvolvida neste artigo - a de como se configura, essencialmente, a relação entre léxico e gramática na Gramática de Construções -, por outro, também emerge, e naturalmente, o potencial de alguma diferença na apreensão dessa relação em investigações específicas, ainda que conduzidas sob esse prisma teórico. Afinal, qualquer pesquisa resulta de recorte observacional, teórico e metodológico definido por um pesquisador mais ou menos alinhado às bases teórico-explicativas que norteiam seu fazer e suscetível a imposições de tempo e infraestrutura, 
bem como adstrito a uma subjetividade (capacidade de percepção, observação, atenção).

Assim, de acordo com a teoria, um padrão construcional, um pareamento forma-significado/função, pode ser mais ou menos esquemático a depender do nível de representação linguística abstrata que se tenha em mente, haja vista o fato de que, conforme Traugott \& Trousdale (2013), os padrões construcionais (ou seja, as construções/unidades mínimas de uma língua) se manifestam em diferentes níveis de esquematicidade/abstração, conforme o quadro (01), abaixo.

\begin{tabular}{|c|c|c|c|}
\hline $\begin{array}{l}\text { Esquemas cons- } \\
\text { trucionais ou Ma- } \\
\text { croconstruções }\end{array}$ & $\begin{array}{c}\text { Subesquemas } \\
\text { construcionais ou } \\
\text { Mesoconstruções }\end{array}$ & Microconstruções & Constructos \\
\hline $\begin{array}{l}\text { os pareamentos } \\
\text { forma-significado/ } \\
\text { função mais ge- } \\
\text { rais e abstratos de } \\
\text { uma rede, os que } \\
\text { contêm mais slots } \\
\text { ("encaixes/espa- } \\
\text { ços" de preenchi- } \\
\text { mento/compati- } \\
\text { bilização de itens } \\
\text { linguísticos. }\end{array}$ & $\begin{array}{l}\text { conjuntos de cons- } \\
\text { truções individuais } \\
\text { com similaridades } \\
\text { observáveis in- } \\
\text { termediários, em } \\
\text { termos de nível es- } \\
\text { quematicidade e } \\
\text { slots a preencher. }\end{array}$ & $\begin{array}{l}\text { construções indivi- } \\
\text { duais mais preen- } \\
\text { chidas/"substan- } \\
\text { tivas" e menos } \\
\text { abstratas, que, em- } \\
\text { bora ainda situadas } \\
\text { num nível represen- } \\
\text { tacional abstrato } \\
\text { da gramática, estão } \\
\text { mais próximas das } \\
\text { expressões que efe- } \\
\text { tivamente se ins- } \\
\text { tanciam em discur- } \\
\text { so/texto, ou seja, } \\
\text { são as que mais } \\
\text { se aproximam dos } \\
\text { usos }\end{array}$ & $\begin{array}{l}\text { ocorrências das } \\
\text { (micro) constru- } \\
\text { ções empirica- } \\
\text { mente verificadas } \\
\text { nos textos ou dis- } \\
\text { cursos, ou seja, } \\
\text { suas instâncias de } \\
\text { uso. }\end{array}$ \\
\hline \multicolumn{3}{|c|}{$\begin{array}{l}\text { Representação abstrata de nosso conhecimento linguísti- } \\
\text { co/Nós construcionais }\end{array}$} & Usos \\
\hline
\end{tabular}

Quadro 1 - Níveis de esquematicidade

Isso significa que há padrões construcionais com mais ou menos slots para preenchimento (em nossa visão, variável) de formas linguísticas, ou seja, (co)lexemas. Dos níveis de 
esquematicidade acima representados, interessam-nos particularmente as macroconstruções e as mesoconstruções, pois a possibilidade de covariação de colexemas se acentua nelas.

Para capturar a relação entre construções de diferentes graus de abstração, a Gramática de Construções prevê, entre outras orientações, estas:

(i) têm estatuto independente e significativo, fonemas (segmentais ou suprassegmentais), morfemas, vocábulos e padrões de organização destes hierarquicamente mais esquemáticos e abstratos ou, em síntese, todas as construções, unidades mínimas de uma língua;

(ii) as formas (gramaticais/procedurais ou lexicais) que podem ocorrer em uma construção devem ser semanticamente compatíveis com o significado da construção ou, mais precisamente, com o significado do espaço/slot da construção em que aquelas são inseridas; (GOLDBERG, 1995, p.59), consoante encaminham os Princípios de Coerência Semântica e de Correspondência.

(iii) segundo o Princípio do Não-Sinonímia"10, "se duas construções são sintaticamente distintas, elas devem ser

10 "If two constructions are syntatically distintic, they must be semantically or pragmatically distinct (Bolinger 1968; (...)). Pragmatic aspects of constructions involve particulars of information structure, including topic and focus, and additionally stylistic aspects of the construction such as register (...). Corollary A: If two constructions are syntatically distintic and $\mathrm{S}$ (emantically)-synonymous, then they must not be $\mathrm{P}$ (ragmatically)-synonymous. Corollary $\mathrm{B}$ : If two constructions are syntatically distinct and P-synonymous, then they must not be S-synonymous" (GOLDBERG, 1995, p.67). 
semanticamente ou pragmaticamente distintas" (GOLDBERG, 1995, p.67); com tal formulação, o princípio registra a potencialidade de similaridade ou semântica ou pragmática.

O norte proposto pelo princípio de não-sinonímia centrase na relação sintaxe-semântica/pragmática das construções. Não obstante, se quisermos ajustar tais atributos aos atributos com base nos quais observamos as faces forma (fonético-fonológica, morfológica, sintática, lexical) e função/significado (semântico, discursivo, pragmático, social e cognitivo) de um pareamento, somos levados a crer na potencialidade de que, em havendo duas construções formalmente distintas, haja entre elas diferença funcional, embora esta não se espraie/ligue, necessariamente, a todos os atributos envolvidos nessa face do pareamento (podendo até ser ou semântica, ou discursiva ou pragmática ou social ou cognitiva). Com isso em mente e com base na ideia de que variação é um fenômeno inerente às línguas (assim como estabilidade e mudança são), entendemos que uma das estratégias metodológicas (também orientada pelo prisma da Gramática de Construções) para exame e detecção do grau de (dis)similaridade (semântica, discursiva, pragmática, social e/ou cognitiva) entre construções é: investigar dados licenciados por essas construções cujos elementos lexicais revelam variação, ou seja, cujos elementos lexicais que 
efetivamente ocupam ou têm o potencial de ocupar os slots de uma construção (por força de analogia ou coerção) se alternam nesse processo de compatibilização a slot de uma construção.

\section{(CO)LEXEMAS E CONSTRUÇÃO: ATRAÇÃO, COERÇÃO E VARIAÇÃO}

Bardðdal (2008), Boyd e Goldberg (2011) e Suttle e Golberg (2011) mencionam que vários fatores são conhecidos por determinarem a produtividade de uma construção. Entre eles, incluem: a frequência de tipo construcional (type); a variabilidade das instanciações atestadas; a similaridade; e a preempção estatística. A produtividade de determinada construção depende de como as instanciações são distribuídas e de seu potencial para essas instâncias (no sentido de uma alternativa 'pré-empacotada', que estatisticamente a antecipa (GOLDBERG, 2013). Esses padrões de frequência são importantes para se identificarem as categorias que são formadas para os slots esquemáticos nas construções.

Para lidar com a relação entre (co)lexemas e construções, focalizaremos as forças de atração e coerção implicadas nessa relação e o fenômeno de variação envolvido nela. Ao fazê-lo, destacaremos os fatores produtividade (com base na experiência de uso, perfil construcional do lexema), 
compatibilização semântica e similaridade ou alinhamento funcional, cujos conceitos foram anteriormente referidos.

Podemos conceber a variação com base em relação de similaridade, que é traçada pelos falantes e/ou é licenciada por conta de links de herança e instanciação. E podemos cogitar de, pelo menos, duas possibilidades de unidades simbólicas submetidas a esse tipo de relação: (1) padrões construcionais e (2) unidades que se compatibilizam em slots de padrões construcionais mais ou menos esquemáticos. ${ }^{11}$

Por ora, concentramos nossa atenção na segunda possibilidade, almejando construiruma discussão quetenciona ser mais representativa que exaustiva das potencialidades do tema. E um caminho que viabiliza lidar com essa expectativa é o exame do significado de construções com base no perfil construcional de seus lexemas ${ }^{12}$, linha de investigação trilhada

\footnotetext{
11 Não concebemos identidade entre padrões construcionais ou entre formas que se compatibilizem no preenchimento do slot de um padrão construcional. Considerar a potencialidade de variação em razão de um certo alinhamento entre propriedades de atributos de pareamentos independentes ou entre propriedades dos elementos linguísticos que se compatibilizam num padrão construcional. Nem mesmo em Sociolinguística encaramos variantes como idênticas, quer seja em decorrência de um dos problemas de investigação na agenda desse modelo (associação das variantes a condicionamentos, de ordem diversa), quer seja em virtude de práticas de investigação científica (ECKERT, 2012) que podem ajudar a desfazer essa ideia (construída na esteira de outras práticas de pesquisa, principalmente da primeira onda da Sociolinguística, que se desenharam a partir de um conceito limitado de mesmo valor de verdade (como identidade) e da associação desse conceito a elementos do plano fonéticofonológico da língua), quer seja em razão da importância que o valor social/estilístico (e também contextual e cognitivo) da variação tem para esse modelo.
}

12 O perfil construcional de um lexema é captado num gráfico que mostre que tal lexema ocorre $\mathrm{X} \%$ das vezes em que se manifesta na construção $\mathrm{C} 1$, Y\% das vezes na construção $\mathrm{C} 2$, $Z \%$ das vezes na construção $C 3$, e assim por diante. Cada porcentagem indica quão frequente a construção dada é para a palavra dada em um corpus específico, e a soma relativa de porcentagens indica o grau em que um lexema está associado a um padrão em particular. 
nas chamadas análises "coleconstrucionais" (collostructional analysis ou collexeme-construction analysis). Tal caminho pauta-se em intuições como: (1) cada lexema tem um perfil construcional; (2) similaridade de significado correlacionase com similaridade de perfil construcional. A segunda intuição enseja que, ainda, cogitemos do seguinte: lexemas quase sinônimos/com significados altamente próximos terão perfis construcionais mais similares do que lexemas menos próximos/equivalentes; lexemas com significados próximos terão perfis construcionais mais similares que lexemas semanticamente não-comparáveis/relacionáveis. $\mathrm{E}$ para lidar com perfis construcionais de modo a examinar a possibilidade de significados relacionados ou não e, uma vez relacionados, mais ou menos similares de certos lexemas, um caminho também é a verificação de colocações lexicais (collocational analysis). Nesse sentido, corpora podem ser explorados para determinar a distribuição relativa de lexemas em construções, bem como técnicas quantitativas (estatísticas) podem ser aplicadas. Aqui, limitamo-nos a expor, sem compromisso estatístico, alguns exemplos morfossintáticos de aspectos envolvidos na pesquisa da relação entre lexemas e construções.

A avaliação de similaridade pode tomar a concepção de escala de prototipicidade ou de semelhança familiar 
como referência na organização das formas lexicais que podem preencher o slot construcional: no primeiro caso, consideramos a existência de membros exemplares/mais centrais da categoria (com similaridade ao protótipo), membros intermediários e membros periféricos (efeitos do protótipo, com poucos traços em comum com a configuração característica da categoria/do protótipo); no segundo, consideramos a definição dos membros da categoria com base em frequência estatística de seus atributos.

O esquema construcional e o protótipo operam, por sua vez, de forma complementar na categorização das unidades. Dessa relação é possível depreender um padrão de comparação, em que se considerem a frequência, produtividade e as outras características discutidas até aqui, e, com isso, medir o grau de esquematicidade de determinada construção, bem como avaliar se determinado lexema é categorizado como uma instanciação ou (re) elaboração deste esquema. No entanto, quando há alguma mudança na relação entre o padrão construcional e o lexema que está sendo categorizado, ou (i) o padrão se manifesta como um protótipo; ou (ii) o relacionamento é de extensão de significado.

Para compreendermos a relação entre a construção e o continuum de prototipicidade, passamos a avaliar os 
resultados da construção de movimento (instanciada com base em enunciados com o verbo partir). Inicialmente, observemos os exemplos (1a) a (1c).

\begin{tabular}{|c|l|}
\hline (1a) & $\begin{array}{l}\text {...fizemos uns desenhos diferenciados lá... e e agora vamo(s) parti(r) } \\
\text { pa cozinha na minha cozinha eu num fiz... [AC-77; DE: L.154] }\end{array}$ \\
\hline (1b) & $\begin{array}{l}\text {..os noivos foram hospitalizados... na Santa Casa de Rio Preto... não } \\
\text { puderam nem parti(r) para a lua-de-mel... ficaram ali... hospitalizados } \\
\text { mas... [AC-113; NR: L.90-91] }\end{array}$ \\
\hline (1c) & $\begin{array}{l}\text { Inf.: tem que tê(r) uma... rivalidade sadia não uma:: rivalidade igno- } \\
\text { rante igual igual tá ten(d)o agora... eu acho que num:: precisa parti(r) } \\
\text { pra esse princípio não de de violência dessas coisa não... [AC-131; RO: } \\
\text { L.257-259] }\end{array}$ \\
\hline
\end{tabular}

Fonte: exemplos extraídos de Wiedemer (2013, p.158).

Considerando (1a) a (1b), dessas, apenas duas ocorrências estão acompanhadas de complemento preposicional, sendo: [lugar], em (1a), e [lugar/evento] em (1b), e a outra ocorrência indica uso mais abstrato do complemento locativo, conforme exemplo em (1c).

Primeiramente, o verbo partir que pressupõe, na sua estrutura argumental (de papéis participantes), um ponto de referência "meta", conforme (1a), passa a admitir outros tipos de complementos locativos mais abstratos, conforme (1b-c). Essa interpretação delineia o processo de especialização dessa construção, e, como consequência da especialização da preposição para, que passa a representar significados gramaticais mais gerais, motivando a generalização 
desse item e, portanto, o processo de mudança semântica, conforme demonstramos abaixo.

Estrutura morfossintática: $\mathrm{SN}_{\text {sujeito }}+\mathrm{SV}$ (partir) [(SNpreposição complemento $_{\text {(S) }}$ ]

(a) Estrutura semântica: Argumento + Predicado + Locativo (meta-destino) (1a)

(b) Estrutura semântica: Argumento + Predicado + Locativo (meta-evento) (2b)

(c) Estrutura semântica: Argumento + Predicado + Locativo (meta-inespecífico) $(3 \mathrm{c})$

Quadro 2 - Estrutura morfossintática do verbo partir e desenvolvimentos semânticos

Avaliando o quadro acima, temos, em (a), a representação semântica de (1a), em que a preposição para atua como introdutora de complemento do verbo partir e se refere a um ponto de chegada ou a um ponto final de referência, ou seja, conceptualiza a indicação de "meta-destino". Já em (b), a representação semântica de (1b), temos um complemento com a significação de "meta-evento", o que confirma os achados de Wiedemer (2013), em relação à configuração do locativo (ponto de referência), em que há uma tendência de condicionamento no padrão de uso de determinada preposição em razão do tipo de complemento. Por fim, em (c), a representação semântica de (1c), o significado do complemento é bastante abstrato em relação a um ponto de referência ou locativo, denominado aqui de "inespecífico".

Assim, os novos significados da preposição para atualizam novos complementos, e, quanto mais abstratos 
os complementos, maior a possibilidade de ocorrência da preposição para na indicação do papel temático "meta", o que deixa a construção mais esquemática e mais produtiva, levando-a à extensão de significado, conforme representado no esquema (01), abaixo. Com isso, a forma para passa a ser a preferida na indicação desses significados, além daquele que originalmente cumpria. Verificamos que esse processo de ampliação de usos da preposição para ocorre com outros verbos (WIEDEMER, 2013, 2014).

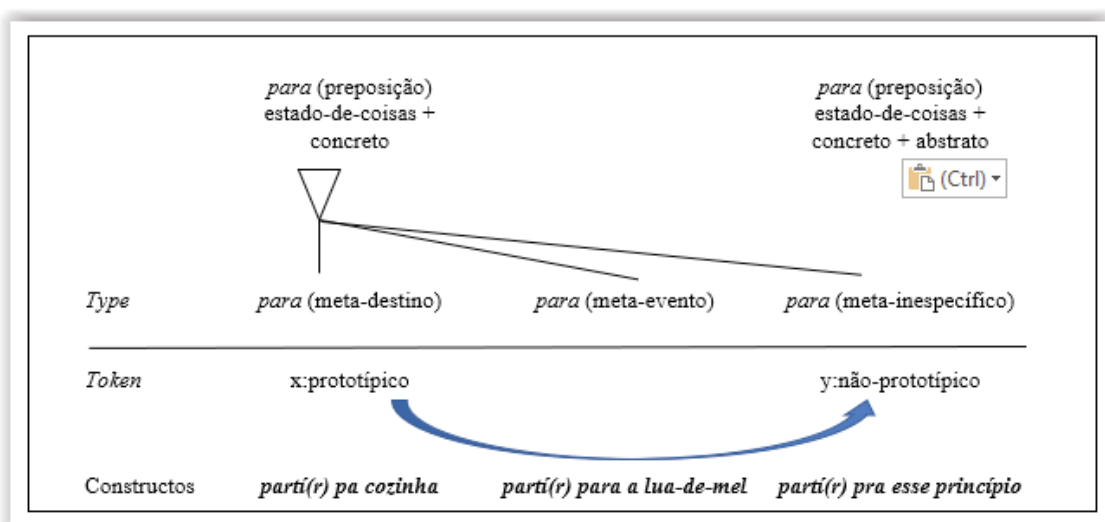

Esquema 1 - Extensão de significado prototípico

Esse conjunto de usos da preposição em combinação com o verbo partir, conforme se observa no esquema acima, permite-nos compreender a questão da prototipicidade aliada ao preenchimento de slots. Se estamos verificando a relação entre (co)lexemas à construção, é necessário enxergarmos o papel do significado do léxico na formação 
da construção. Como construções, subesquemas e esquemas, são resultados de categorização e abstração mentais, determinados usos podem, até certo ponto, pertencer a determinada construção, como pertencem os exemplos (1a) e (1b), em que é visto o esquema construcional de movimento. Se voltarmos à análise desses dois usos, apesar dos lexemas (cozinha) e (lua-de-mel) possuírem traços semânticos que os diferenciam no nível microconstrucional, ambos podem ser conceptualizados como "lugar", ou seja, "ponto de referência”, em que enxergamos claramente a ideia de relação entre figura/fundo de o objeto da ação e o ponto de referência. Já em (1c), temos uma expansão do sentido da construção, em que classificamos o papel participante como "estado de coisas abstrato", pois da mudança semântica do significado de movimento, em que se tem a ideia de um movimento mais abstrato, a microconstrução (1.3) passa a desempenhar a ideia de finalidade, além da ideia de movimento. Este gradiente decorre de motivações pragmáticas, conforme a proposta de Traugott (1999), reafirmada em Traugott e Dasher (2002), de um modelo denominado Teoria da Inferência Sugerida para a Mudança Semântica (TISMS), segundo o qual os casos de mudança semântica podem ser tratados de forma unificada como em determinadas situações em que uma dada forma codificadora de um dado significado 
passaria a ser polissêmica, e, consequentemente, a codificar novos significados relacionados ao significado anterior ou motivados por ele.

Assim, numa primeira análise, temos a construção nãoprototípica (1c) que deriva da primeira construção (1a), principalmente, por força de analogização, à qual é atribuído um novo significado ou forma a partir de representações exemplares ou atratoras. De acordo com Traugott \& Trousdale (2013), trata-se de novos alinhamentos de sentido e forma na base de outros já existentes. Essas alterações de forma/significado acontecem em pequenos passos discretos (gradualidade ao longo do tempo), resultando em variação (gradiência).

Como a gramática consiste em construções, os signos linguísticos são categorias prototípicas. E o protótipo de uma construção é caraterizado pelo significado do lexema fortemente associado a uma construção. Assim, quanto maior a força de associação de determinado lexema à construção, mais prototípico; quanto menor, menos prototípico. Procuramos representar, na Figura (1), essa questão. 


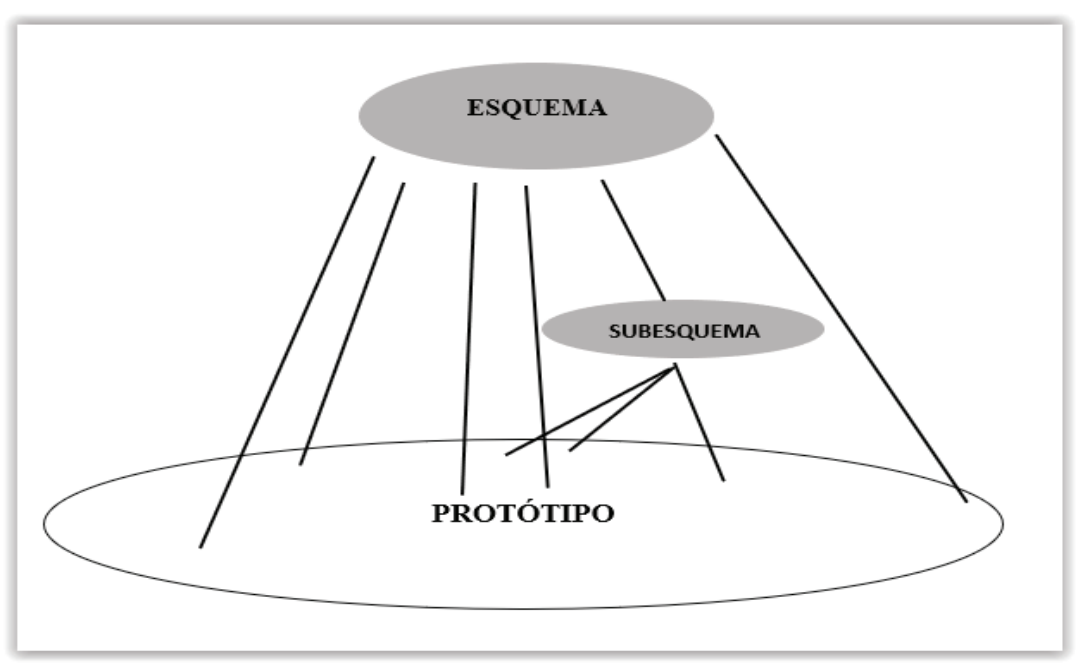

Figura 1 - Relação entre esquema, subesquema e protótipo Fonte: Adaptado de Winters (1992).

Após avaliarmos o binômio construção/prototipicidade, ainda precisamos evidenciar que um slot construcional conta com condicionamentos de preenchimento, que podem operar na relação com outros advindos da combinação com outro(s) slot(s) da mesma construção ou de propriedades que se resolvem no momento de sua instanciação. Como as construções gramaticais são relacionais por natureza, pois sempre apresentam esquematicidade e produtividade, elas podem, ao longo tempo, vir a ser usadas com amplo número de colocações. Himmelmann (2004) denomina de host-class (classe hospedeira) e Bardðdal (2008) considera essa nova "adição" de lexema à construção como "extensibilidade do esquema". 
Para tanto, passamos aos resultados da pesquisa de Pereira (2016), mais especificamente à análise do slot verbal em construção perifrástica de fase aspectual [VERBO semiauxiliar aspectual (não)finito PREPOSIÇÃO VERBO ${ }_{2 \text { no infinitivo }}$ ].

De acordo com a pesquisa de Pereira (2016), atualizam-se diferentes verbos semiauxiliares no slot verbal da construção perifrástica de aspecto (inceptivo e terminativo) [VERBO semiauxiliar aspectual (não)finito PREPOSIÇÃO $V E B_{2}$ no infinitivo $] e, e m$ função dos verbos semiauxiliares que a instanciam, padrões construcionais por ela licenciados sinalizarão diferentes nuances de significado no eixo objetificação-subjetificação. Na análise dessas diferenças a partir de dados do uso, a autora chega a identificar um conjunto de cinco microconstruções de aspecto inceptivo e três microconstruções de aspecto terminativo, de que destacaremos alguns aspectos ${ }^{13}$ no intuito de priorizar o que, no tema, indica o fenômeno da variação de colexemas.

A autora descreve, por exemplo, estas microconstruções: (i) a microconstrução de início com foco neste ponto e expectativa de desenvolvimento e (ii) a microconstrução com foco na velocidade e intensidade da mudança, entre as microconstruções a serviço de marcar fase inicial; e

13 Para o conhecimento da rede construcional de marcação de aspecto inceptivo ou terminativo, recomenda-se a leitura da dissertação da autora ora referida. 
(iii) a microconstrução com foco na interrupção, entre as microconstruções que se prestam a indicar fase final.

Ao apresentar os atributos da primeira, a autora (PEREIRA, 2016, p.125) destaca estes: "uma perspectiva mais referencial/ objetiva de representação do estado de coisas a partir de seu início, focalizando precisamente este ponto de referência e estabelecendo uma expectativa de seu desenvolvimento (e até conclusão) do evento ou situação expressos por $V_{2}$ ". $E$, então, passa a mostrar os verbos que, nessa condição de conceptualização, preenchem $\mathrm{V}_{1}$ : começar, iniciar, estrear, principiar e mover-se. Desses, a autora ressalta "começar" como altamente frequente em todas as modalidades expressivas e variedades pesquisadas (Português do Brasil e de Português de Portugal) e o verbo geralmente mais atraído pelo slot construcional $\mathrm{V}_{1}$ na marcação de fase inicial.

Ao expor os atributos da segunda, a autora delineia estes:

também focaliza a momentaneidade do ponto inicial e o desenrolar do estado de coisas representado por $\mathrm{V}_{2}$. No entanto, a particularidade aqui presente é o modo como se inicia esse evento ou situação, que é veloz, e como se desenvolve o mesmo, de maneira intensa. (PEREIRA, 2016, p.125-126)

E, então, lista os verbos que, nessa condição de conceptualização, aparecem em $\mathrm{V}_{1}$ : desatar, deslanchar, 
romper, lançar-se e sair. Segundo a autora, dados com tais verbos são de difícil registro em textos, embora sejam usados ou viáveis (uma vez que são encontrados, via pesquisa na internet, em $V_{1}$, mesmo que alguns nem expressão tenham tido no corpus constituído para as finalidades da pesquisa).

Ao tratar dos atributos da terceira, a autora (PEREIRA, 2016: p.126) salienta estes: "realça o ponto final de um estado de coisas a partir de seu não complemento, ou seja, da sua interrupção. Dessa forma, ilumina também a possibilidade de retomada do evento ou situação em questão". E, então, cita os verbos que, nessa condição de conceptualização, aparecem em $\mathrm{V}_{1}$ : parar e cessar. Desses, a autora revela que "parar"14 é o verbo que mais frequentemente é acionado em Português e, portanto, o verbo mais atraído pelo slot construcional $\mathrm{V}_{1}$.

A pesquisadora (PEREIRA, 2016, p.99-115) trata, ainda, da relação do verbo semiauxiliar com outros slots da construção de marcação de fase aspectual ou propriedades do entorno em que se instancia tal construção. Tem destaque, por exemplo, a configuração de $V_{2}$. E, ao descrever esta sob diferentes atributos, a autora menciona, por exemplo, a possibilidade de os verbos que aparecem na microconsrução (i) acompanharem, inclusive, $\mathrm{V}_{2}$ com traço de duratividade negativo (porque designa

14 Loiola (2018), que também se dedicou ao estudo do tema só que diacronicamente, encontrou, entre as cessativas, parar mais frequentemente que cessar na escrita do século XX $\mathrm{e}$ menos frequentemente que cessar na escrita do século XIX. 
evento, dinâmico, não-faseável/pontual), "em que o início e o fim da ação se dão em intervalo de tempo desconsiderável e indescritível de tão curto" (p.100). E isso ocorre por conta da combinação, no momento da instanciação dessa construção, de certa propriedade ligada à configuração do constituinte sujeito (condição de plural no sujeito), como se nota no primeiro dos exemplos por ela citados e comparados "Pedro e seus amigos começaram a chegar" e "Pedro começou a chegar."

Os destaques dessa obra ora feitos ajudam-nos a exemplificar formas em co-variação num slot construcional. E mostram tanto formas mais similares/colexemas e, então, mais esperadas por conta das condições de preenchimento do slot construcional e por força de tendências de uso no Brasil quanto formas menos alinhadas às condições de preenchimento e, então, menos atraídas pelo slot/lexemas, mas que, por força do uso (mesmo menos esporádico), são associadas ao slot construcional, e, então, por força de coerção (da construção), são alinhadas às mais produtivamente implicadas em tal slot.

Além da prototipicidade e da produtividade de determinado slot, outros fatores estão relacionados ao processamento das construções, além da rotinização (frequência), tais como a saliência perceptual das formas 
linguísticas e dos referentes extralinguísticos, bem como a saliência cognitiva dos conceitos (GEERAERTS, GRONDELAERS \& BAKEMA, 1994).

Se avaliarmos que as formas salientes e os referentes mais frequentes são mais propensos a atrair a atenção e, portanto, são rotinizados no discurso, eles também se sujeitam mais a entrincheiramento e, por sua vez, passam a apresentar maior grau de esquematicidade e produtividade. Uma vez entrincheirados, esses esquemas são mais facilmente ativados, com menor esforço cognitivo e, portanto, têm maior probabilidade de serem repetidos. Por exemplo, Goldberg (2013) afirma que outro papel importante na representação de uma construção é aceitar a ideia de exemplares, ou seja, a autora indica para o uso dos lexemas e a maneira como os slots de uma construção se expandem. Sobre isso:

Um slot esquemático em uma construção pode consistir em uma lista de todos os itens que ocorreram naquele slot (como previsto por um modelo de exemplares), ou pode ser considerado um conjunto de traços semânticos abstratos que restringe o slot, como usualmente proposto. Poderia, claro, ser ambos. No entanto, a importância dos exemplares específicos, que tenham ocorrido na construção, pode ser vista 
quando traços que são redundantes para itens particulares são referidos em uma extensão da construção ${ }^{15}$.

Assim, um papel importante dos exemplares na representação de uma construção é verificar como se expandem os slots de determinada construção. Sobre isso, Bybee (2013) comenta que um slot esquemático em uma construção pode consistir em uma lista de todos os itens que ocorreram naquele slot (conforme previsto pelo Modelo de Exemplares), ou ele pode ser considerado um conjunto de traços semânticos abstratos que restringem o slot. Podemos, portanto, de acordo com Traugott \& Trousdale (2013), distinguir um esquema (= uma construção complexa, com slots abertos) do nível de esquematicidade de uma construção (= o grau em que uma construção é fonologicamente subespecificada e semanticamente geral).

Conforme indicado em Machado Vieira \& Wiedemer (2018), o conceito de produtividade, no modelo de gramática de construções baseada no uso, refere-se à produtividade de determinada construção que é conduzida por um esquema abstrato a partir de enunciados reais, o que nos

15 Original: "A schematic slot in a construction might consist of a list of all the items that have occurred in that slot (as predicted by an exemplar model), or it might be considered a set of abstract semantic features that constrains the slot, as usually proposed. It could, of course, be both. However, the importance of the specific exemplars that have occurred in the construction can be seen when features that are redundant for particular items are referred to in an extension of the construction" (GOLDBERG, 2013, p.57). 
permite compreender a relação entre a produtividade de um padrão construcional e o número de itens que naquele se compatibilizam, nomeado de type frequency da construção. De acordo com os autores (MACHADO VIEIRA \& WIEDEMER (2018, no prelo, s/p.):

A partir dos parâmetros produtividade e esquematicidade, outro tipo de analogia é a paradigmática, que se delineia em razão do processo de compatibilização de unidades linguísticas em slots abertos a que se sujeitam padrões construcionais e da fixação de um "padrão paradigmático", que passa a orientar a formulação de expressões linguísticas com base num mesmo significado (região funcional/ enquadre cognitivo com especificações que servem de orientação para o uso da língua).

Por outro lado, a repetição de tokens idênticos (token frequency) leva ao maior entrincheiramento, em termos de força de representação, enquanto a repetição de itens variados, que compartilham forma e/ou significado (type frequency) leva a categorização, abstração, generalização e promove o surgimento de esquemas variáveis (GOLDBERG, 2006). Sobre o assunto, Schmid (2016), ao analisar a relação entre entrincheiramento, memória e automaticidade, assinala que a repetição de uma sequência fixa fortalece a representação desse complexo forma-significado/função, 
enquanto a repetição de expressões (por exemplo, me dá (ou dê) a boneca, me dê o livro, me dê o copo, etc.) promove a formação de um esquema variável "me dê X". Assim, de acordo com o autor (2016 - grifos nossos):

O processo de esquematização requer uma interação intrincada de uma associação simbólica emergente entre formas e significados/funções, de associações sintagmáticas entre as partes componentes de um esquema (por exemplo, gimme $+X$ ) e das associações paradigmáticas entre os elementos que podem preencher o slot variável em um esquema (o boneco, o livro, o copo). Essas associações paradigmáticas, que se baseiam nos processos psicológicos de comparação e analogia, também constituem o ponto de partida para o surgimento de categorias gramaticais como classes de palavras (...) e para a dimensão paradigmática das redes lexicais $^{16} \cdot(p .5)$

Soma-se a isso que a frequência type de esquemas variáveis também pode apresentar efeitos aparentemente contraditórios, conforme indicado por Bybee (2015). Por um lado, a alta frequência type facilita a emergência

16 Original: The process of schematization requires an intricate interplay of an emerging symbolic association between forms and meanings/functions, of syntagmatic associations between the component parts of a schema (e.g. gimme $+X$ ) and of the pa-radigmatic associations between the elements that can fill the variable slot in a schema (the doll, the book, the cup). These paradigmatic associations, which are based on the psychological processes of comparison and analogy, also make up the starting point for the emergence of grammatical categories such as word-classes (...) and for the paradigmatic dimension of lexical networks. 
de surgimento de construções - Construcionalização, nos moldes de Traugott \& Trousdale (2013) -, pois os slots variáveis têm o efeito de facilitar o processo de produtividade (Mary me assou um bolo), que promove o potencial de inovação (Mary me deu um beijo) e fornece a base para mudança analógica. - Analogização, nos moldes de Traugott \& Trousdale (2013) -. Por outro lado, a alta frequência de slots variáveis é fortemente representada como concorrentes paradigmáticos; e, portanto, os lexemas são selecionados preferencialmente quase por um padrão (por exemplo, construção (di)transitiva, Mary me deu o livro), e funcionam como atratores analógicos para lexemas menos frequentes e contribuem para a resistência à mudança linguística (BYBEE, 2006, 2010; TRAUGOTT, 2008).

Como vimos, a ideia de usar a frequência para explicitar a distribuição (potencial) de uma construção permite ao analista determinar a produtividade de um esquema, o que é medido pela determinação de quantos itens diferentes ocorrem nos vários slots esquemáticos de uma construção. Além disso, capturar a descrição detalhada de uma construção também não incluíra tão somente a atração e frequência em determinado slot, mas também as restrições implicadas pela semântica dos lexemas que compõem determinada construção. Além disso, tais colexemas fornecem evidências 
de que a construção não armazena e processa simplesmente construções em nível mais geral, mas também é capaz de armazenar exemplares, mesmo que esses exemplares herdem todas as suas propriedades formais de uma construção mais geral, conforme já exposto na pesquisa de CristófaroSilva \& Gomes (2004), em que se referem à existência da multirepresentacionalidade das formas linguísticas e sugerem que a organização do conhecimento linguístico seja probabilisticamente gerenciada.

\section{(CO)LEXEMAS E CONSTRUÇÃO: COLOCAÇÃO E ANÁLISE DE COLEXEMAS}

Segundo Hilpert (2014), uma análise colocacional de construções é motivada pela percepção de que o significado de uma construção tende a se harmonizar com os significados dos elementos lexicais que normalmente ocorrem nela. Ainda sobre o assunto, o autor esclarece que a análise colocacional de construções é um termo utilizado para reunir três métodos da investigação de linguística de corpus, que investiga a associação entre construções gramaticais e itens lexicais, conforme o quadro (2). 


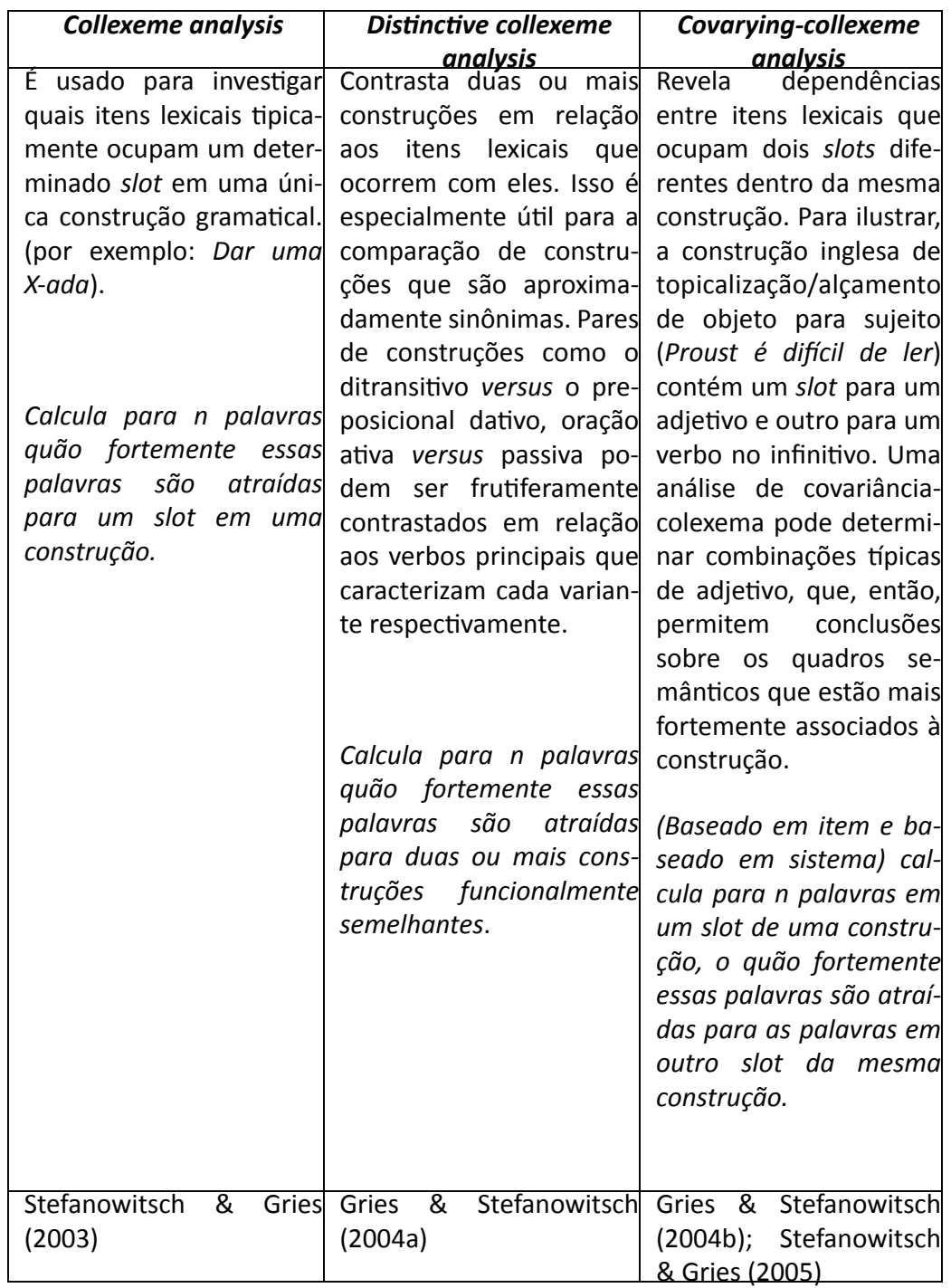

Quadro 2 - Métodos de análise de colocação construcional Fonte: Adaptado de Hilpert (2014).

Todos esses métodos fornecem classificações de quanto os lexemas e os slots de construção se atraem; e revelam sobre 
a semântica estrutural, conforme amplamente comprovado por Hilpert (2006, 2008). Dessa forma, é possível associar essa abordagem ao tratamento da variação no modelo construcional e validar que a Gramática de Construções pode abarcar, em suas pesquisas, caminhos teórico-metodológicos que promovam o detalhamento da variação pelo modelo.

Vale saber que a análise de colexemas (collexeme) foi introduzida por Stefanowitsch e Gries (2003, p.20) como "uma extensão da análise colocacional especialmente voltada para investigar a interação entre lexemas e as estruturas gramaticais associadas a eles ${ }^{17 \prime \prime}$, e consiste em verificar as palavras (itens lexicais) que ocorrem em um dado slot de uma construção e, mais particularmente: "determinar o grau em que determinados slots em uma estrutura gramatical são preferidos ou restritos a um conjunto particular ou uma classe semântica de itens lexicais"18 (p.211). São exemplos de aplicação da análise de colexemas, os estudos sobre frames (GRIES \& STEFANOWITSCH, 2004), sobre protótipos (STEFANOWITSCH \& GRIES, 2005), estudo da variação sociolinguística (WULFF, STEFANOWITSCH \& GRIES, 2007).

Como o propósito aqui é destacar a correlação entre (co)lexemas e construção, interessa-nos depreender a

17 Original: "an extension of collocational analysis specifically geared to investigating the interaction of lexemes and the grammatical structures associated with them".

18 Original: "determining the degree to which particular slots in a grammatical structure prefer, or are restricted to, a particular set or semantic class of lexical items". 
análise da relação de similaridade entre as possibilidades de preenchimento, bem como a frequência/produtividade de compatibilização de um (co)lexema em um slot de uma dada construção em relação aos (co)lexemas que se associam a um outro slot diferente da mesma construção. Para tanto, abaixo, avaliamos as construções de movimento do português brasileiro $\left[\mathrm{SN}+\mathrm{SV}\left[\left(\mathrm{SNpr}_{\text {complemento }}\right)\right]\right.$, mais especificamente, as construções formadas com os verbos entrar, ir, levar e voltar, que são complementadas pelas preposições $a$, para e em a partir dos resultados de Wiedemer (2013).

Como estamos considerando que um determinado slot apresente força atratora ou de coerção, nosso interesse recai na relação entre o esquema abstrato da construção, ou seja, a construção de movimento, e o preenchimento de seus lexemas. Dessa forma, primeiramente, realizamos a classificação das características do ponto de referência (locativo), que se mostram relevantes para o uso alternante das preposições a/para/em. Assim, detalhamos a configuração do espaço, tentando captar diferenças mais sutis e detectar eventuais condicionamentos de coerção ou atração/repulsa de determinado (co)lexema. A proposição desse grupo de fatores leva em conta, especialmente, os resultados apresentados em Wiedemer (2013), que demonstrou haver a atuação favorável desse fator no condicionamento 
da seleção de determinada preposição que complementa o verbo de movimento. Dessa forma, percebemos que os traços semânticos do complemento locativo/ponto de referência ${ }^{19}$ atuam na seleção das preposições, o que evidencia o caráter esquemático.

Inicialmente, evidenciamos a classificação dos complementos locativo/ponto de referência, conforme proposto em Wiedemer (2013), em que adotou a seguinte classificação: (a) [objeto] - remete a objetos sem nomes definidos (exemplos: cadeira, arquibancada); (b) [instituição] - remete a nomes definidos de lugares (exemplo: UNESP); (c) [instituição personificada] - remete tanto à personificação de instituição (médico = consultório) quanto à personificação de lugar (sogra = casa da sogra); (d) [evento] - refere-se a eventos que ocorrem em certos lugares (exemplos: missa, futebol,festa); (e) [espaço sócio-geográfico] - designa lugares geograficamente definidos (exemplo: Paraguai); (f) [lugar] - remete ao ponto de referência definido espacialmente (exemplos: centro, interior). São alguns outros exemplos:

19 "em relação ao complemento locativo/ponto de referência, caracterizamos o que podemos chamar de "configuração do espaço", definida por diferentes propriedades semânticas que, conjuntamente, configuram os espaços que compõem as situações representadas pelos complementos dos verbos de movimento. Essas propriedades são controladas a partir da identificação dos fatores semântico-discursivos que compõem a variável Configuração do complemento locativo/ponto de referência" (WIEDEMER, 2013, p.146). 


\begin{tabular}{|c|l|}
\hline (2a) & $\begin{array}{l}\text {...espera esfriá(r) um po(u)quinho cê pode tá levran/ levando à } \\
\text { geladei::ra ou ao freezer pra ele esfriá(r) mai... [objeto] [AC-040; RP: } \\
\text { L-96-97] }\end{array}$ \\
\hline (2b) & $\begin{array}{l}\text {...porque quan/ quando (a gente foi) pra lá a gente passô(u) por } \\
\text { Reci::fe né? depois agente foi pra Natal então... [espaço geográfico] } \\
\text { [AC-044; DE: L-157-158] }\end{array}$ \\
\hline (2c) & $\begin{array}{l}\text {.. aí num tem que esperá(r)... mas eu... sábado mesmo ele foi num } \\
\text { baile né?... [Doc.: aham ((concordando))] [evento][AC-058; RP: L.287- } \\
288]\end{array}$ \\
\hline
\end{tabular}

Fonte: Exemplos extraídos de Wiedemer (2013, p.182).

Após a classificação dos complementos locativos/ponto de referência, tem-se o controle dessa variável sobre o uso das preposições (a/para/em) e sua relação com os verbos de movimento selecionados, conforme os resultados dispostos na tabela (01). 


\begin{tabular}{|c|c|c|c|c|c|c|c|c|c|c|c|}
\hline \multirow[t]{2}{*}{ Verbo } & \multirow{2}{*}{$\begin{array}{l}\text { Configuração } \\
\text { Ponto de } \\
\text { referência } \\
\end{array}$} & \multicolumn{4}{|c|}{$\mathbf{A}$} & \multicolumn{3}{|c|}{ PARA } & \multicolumn{3}{|c|}{ EM } \\
\hline & & Apl./total & $\%$ & PR & Apl./total & $\%$ & PR & & pl./total & $\%$ & PR \\
\hline & Lugar & $0 / 0$ & 0 & - & $7 / 102$ & 6.9 & 0.44 & & $95 / 102$ & 93.1 & 0.558 \\
\hline \multirow{5}{*}{ ENTRAR } & Objeto & $0 / 0$ & 0 & - & $0 / 9$ & 0 & - & & $9 / 9$ & 100 & - \\
\hline & Instituição & $0 / 0$ & 0 & - & $1 / 13$ & 7.7 & 0.473 & & $12 / 13$ & 92.3 & 0.527 \\
\hline & Inst.personif. & $0 / 0$ & 0 & - & $5 / 14$ & 35.7 & 0.85 & & $9 / 14$ & 64.3 & 0.143 \\
\hline & Evento & $0 / 0$ & 0 & - & $0 / 25$ & 0 & - & & $25 / 25$ & 100 & - \\
\hline & Espaço geog. & $0 / 0$ & 0 & - & $0 / 9$ & 0 & - & & $9 / 9$ & 100 & - \\
\hline TOTAL & & & & & $13 / 172$ & 7.6 & & & $59 / 172$ & 92.4 & \\
\hline \multicolumn{2}{|c|}{ Significância } & & & & & & & & \multicolumn{3}{|c|}{ Input: 0.915 Sig.: 0.011} \\
\hline \multirow[t]{2}{*}{ Verbo } & \multirow{2}{*}{$\begin{array}{c}\text { Configuração } \\
\text { Ponto de } \\
\text { referência }\end{array}$} & \multicolumn{3}{|c|}{$\mathbf{A}$} & \multicolumn{3}{|c|}{ PARA } & & \multicolumn{3}{|c|}{ EM } \\
\hline & & Apl./total & $\%$ & $\mathbf{P R}$ & Apl./total & $\%$ & $\mathbf{P}$ & $\mathbf{R}$ & Apl./total & $\%$ & PR \\
\hline & Lugar & $4 / 243$ & 1.6 & 0.382 & $111 / 243$ & 45.7 & 0.4 & 447 & $128 / 243$ & 52.7 & 0.573 \\
\hline \multirow{5}{*}{ IR } & Objeto & $4 / 33$ & 12.1 & 0.835 & $11 / 33$ & 33.3 & 0.3 & 324 & $18 / 33$ & 54.5 & 0.591 \\
\hline & Instituição & $1 / 53$ & 21.9 & 0.415 & $28 / / 53$ & 52.8 & 0.5 & 518 & $24 / 53$ & 45.3 & 0.500 \\
\hline & Inst.personif. & $1 / 39$ & 2.6 & 0.492 & $17 / 39$ & 43.6 & 0.4 & 426 & $21 / 39$ & 53.8 & 0.584 \\
\hline & Evento & $4 / 57$ & 7 & 0.735 & $15 / 57$ & 26.3 & 0.2 & 255 & $38 / 57$ & 66.7 & 0.707 \\
\hline & Espaço geog. & $5 / 163$ & 3.1 & 0.538 & $117 / 163$ & 71.8 & 0.7 & 709 & $41 / 163$ & 25.2 & 0.289 \\
\hline \multicolumn{2}{|l|}{ TOTAL } & $19 / 588$ & 3.2 & & $299 / 588$ & 50.9 & & & $270 / 588$ & 45.9 & \\
\hline \multicolumn{2}{|c|}{ Significância } & \multicolumn{3}{|c|}{ Input: 0.026 Sig.: 0.086} & \multicolumn{4}{|c|}{ Input: 0.510 Sig.: 0.000} & \multicolumn{3}{|c|}{ Input: 0.453 Sig.: 0.000} \\
\hline \multirow[t]{3}{*}{ Verbo } & \multirow{2}{*}{$\begin{array}{c}\text { Configuração } \\
\text { Ponto de } \\
\text { referência }\end{array}$} & \multicolumn{3}{|c|}{$\mathbf{A}$} & \multicolumn{3}{|c|}{ PARA } & & & EM & \\
\hline & & Apl./total & $\%$ & $\mathbf{P R}$ & Apl./total & $\%$ & & PR & Apl./total & $\%$ & PR \\
\hline & Lugar & $4 / 72$ & 5.6 & 0.340 & $40 / 72$ & 55. & & 0.570 & $28 / 72$ & 38.9 & 0.514 \\
\hline & Objeto & $13 / 27$ & 48.1 & 0.890 & $10 / 27$ & 37 & & 0.384 & $4 / 27$ & 14.8 & 0.225 \\
\hline & Instituição & $1 / 22$ & 4.5 & 0.294 & $7 / 22$ & 31. & & 0.331 & $14 / 22$ & 63.6 & 0.744 \\
\hline LEVAR & Inst.personif. & $4 / 29$ & 13.8 & 0.583 & $13 / 29$ & 44. & & 0.463 & $12 / 29$ & 41.41 & 0.540 \\
\hline & Evento & $1 / 9$ & 11.1 & 0.522 & $3 / 9$ & 33. & & 0.347 & $5 / 9$ & 55.6 & 0.675 \\
\hline & Espaço geog. & $0 / 22$ & 0 & - & $15 / 22$ & 68. & & 0.694 & $7 / 22$ & 31.8 & 0.437 \\
\hline TOTAL & & $23 / 181$ & 12.17 & & $88 / 181$ & 48.6 & & & $70 / 181$ & 38.7 & \\
\hline Significância & & Input: 0.1 & 3 Sig.: & 0.000 & Inpu & 0.485 & Sig.: 0. & .083 & Input: 0. & $0.375 \mathrm{Sig}$ & g.: 0.013 \\
\hline Verbo & $\begin{array}{c}\text { Configuração } \\
\text { Ponto de } \\
\text { referência } \\
\end{array}$ & & $\mathbf{A}$ & & & $\mathbf{R A}$ & & & & $\mathrm{EM}$ & \\
\hline & & Apl. & total & $\%$ & PR & l./total & $\%$ & PR & Apl./tota & $\%$ & PR \\
\hline & Lugar & $1 /$ & & 2.4 & 0.435 & $5 / 42$ & 83.3 & 0.529 & $6 / 42$ & 14.3 & 0.494 \\
\hline & Objeto & $1 /$ & & 33.3 & - & $2 / 3$ & 66.7 & - & $0 / 0$ & 0 & - \\
\hline & Instituição & 0 & & 0 & - & $0 / 2$ & 0 & - & $2 / 2$ & 100 & - \\
\hline VOLTAR & Inst.personif. & $1 /$ & & 16.7 & 0.863 & $4 / 6$ & 66.7 & 0.310 & $1 / 6$ & 16.7 & 0.539 \\
\hline & Evento & 2 & & 40 & - & $3 / 5$ & 60 & - & $0 / 0$ & 0 & - \\
\hline & Espaço geog. & $0 /$ & & 0 & - & $3 / 17$ & 76.5 & - & $4 / 17$ & 23.5 & - \\
\hline TOTAL & & $5 /$ & 75 & 6.7 & & $/ 75$ & 76 & & $13 / 75$ & 17.3 & \\
\hline Significânc & & Inpt & t: 0.031 & Sig.: 0.1 & 136 & put: 0.8 & 17 Sig.: & $\therefore 0.206$ & Input: 0 & $0.146 \mathrm{Sig}$ & g.: 0.609 \\
\hline
\end{tabular}

Tabela 1 - Influência da variável configuração do complemento locativo/ponto de referência sobre o uso de a/para/em na introdução de complementos de verbos de movimento (Amostra Iboruna). Fonte: Wiedemer (2013, p.181). 
Os resultados dispostos, acima, oferecem a frequência de uso dos diferentes complementos, bem como o peso relativo/ significância estatística em cada construção analisada.

Primeiramente, de acordo com Wiedemer (2013), a configuração do espaço locativo/ponto de referência revela um resultado interessante, à medida que correlaciona o emprego de para a locativos representados por instituição personificada (P.R. 0.85) e o emprego de em a locativos representados por lugar, propriamente ditos. Segundo o autor, no que concerne ao verbo voltar, os resultados mostram que complementos com a semântica [objeto] e [evento] não selecionam a preposição em; por outro lado, pontos de referência que denominam [espaço geográfico] ou [instituição] não selecionam a preposição $a$. O fator [instituição personificada] condiciona a seleção tanto da preposição a (P.R. 0.86) quanto da preposição em (P.R. 0.53). Já a preposição para é condicionada pelo fator [lugar]. Para o verbo ir indicam o seguinte padrão de correlação: a preposição a está correlacionada com completo [objeto], para com [espaço geográfico], e em com [evento]. No caso do verbo levar, o fator [objeto] é relevante também na seleção da preposição a (P.R. 0.89), ao passo que a seleção das preposições para e em são motivadas, respectivamente, pelos fatores [espaço geográfico] e [evento]. 
Anteriormente, verificamos o peso relativo de cada lexema e seu condicionamento no uso preposicional, ou seja, evidenciamos a atuação do grau de esquematicidade da construção, aqui analisada. Agora, cabe ainda analisarmos a força de coerção de cada lexema (SNpreposicional), em que procuramos evidenciar a sua força coercitiva na construção de movimento. Para tanto, evidenciamos os pesos relativos como forças atratoras desses lexemas, que são perfilados para o slot na construção, conforme evidenciado no esquema, abaixo.

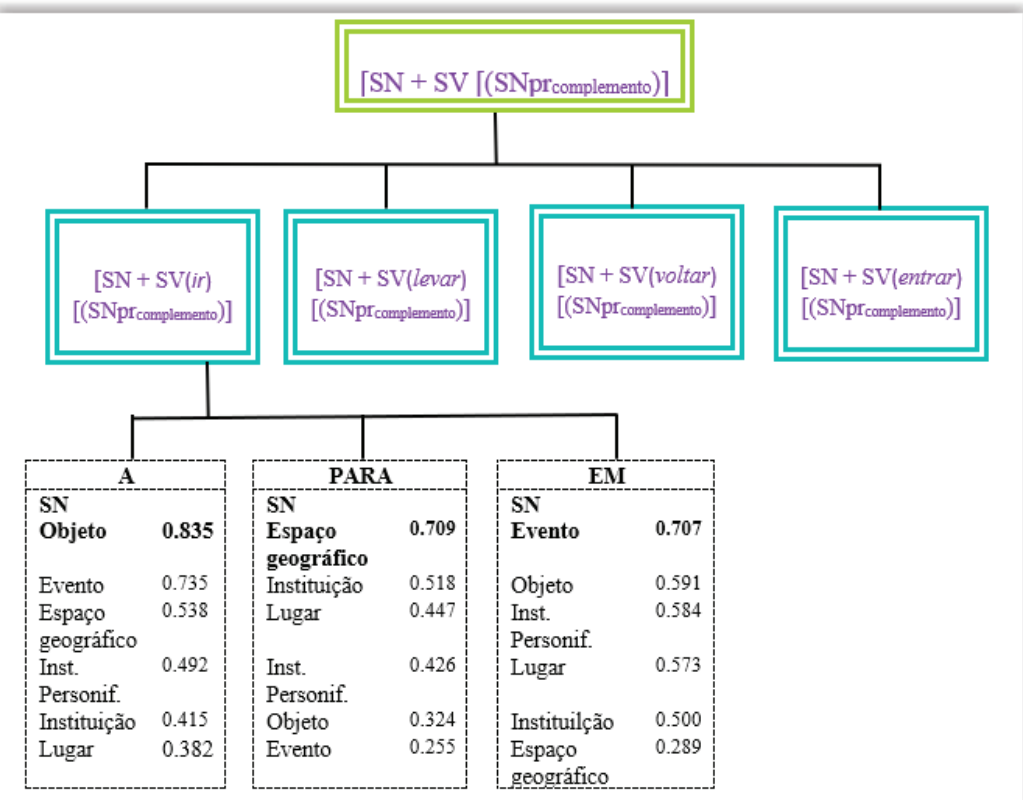

Esquema 2 - Relação de força atrativa/coerção de (co)lexemas e construção 
Se observarmos os resultados, é possível depreender que as propriedades semânticas ou formais de um slot determinam sua esquematicidade. Um slot altamente esquemático, como a configuração do espaço/ponto de referência, tem um amplo conjunto de propriedades. Além disso, demonstram que, se avaliarmos a força atratora dos lexemas da construção de movimento, estes demonstram, particularmente, que há grupos de itens que estão intimamente relacionados e que são atraídos pela construção.

Além de olharmos para a lista de lexemas atraídos, é necessário considerar os itens repelidos pelo slot e suas propriedades. A ausência relativa de certos lexemas em uma construção pode fornecer pistas sobre as restrições que governam seu uso. Um exemplo disso é percebido se comparamos os (co)lexemas relacionados ao slot do verbo ir, que permite, pelo menos, três usos preposicionais ( $a$, para, em). Por outro lado, retomando os resultados da tabela (01), vimos que o verbo entrar está associado às preposições para e em, ou seja, apresenta restrição semântica, que motiva a coerção do item lexical $a$. Interessante notar que, apesar de não possuir frequência de uso da preposição $a$, a construção de movimento com verbo entrar permite avaliarmos os mesmos slots para as preposições para e em, o que comprova o caráter mais abstrato e esquemático da construção de movimento. 
Os resultados apresentados acima têm implicações para a teorização linguística e para a Gramática de Construções, pois mostram que há dependências entre (co)lexemas e construções a serem investigadas, o que fornece subsídios para o tratamento da variação a partir de um repositório de unidades linguísticas com variados graus de similaridade ou de especificidade. As diversas conexões entre (co)lexemas e construções, e de diferentes tipos, possibilitam-nos perceber que essas conexões estão sujeitas a adequação lexical em termos de força relativa. Dessa forma, a análise oferece ao pesquisador a possibilidade de verificar a variação no modelo construcional, e fornece uma quantificação do grau de atração/repulsa dos (co)lexemas, bem como o rastreamento sobre quais colexemas estão mais propensos à construção e de que lexemas têm o potencial se moldarem à força da construção. Assim, a gama de resultados viabilizados mediante uma análise de colexemas, de sua colocação numa construção, oferece novos encaminhamentos teóricometodológicos para o tratamento da variação.

\section{CONSIDERAÇÕES FINAIS}

Tanto o controle do tipo de (co)lexemas quanto o controle da frequência simbólica (type/token) são importantes para a compreensão das construções, pois ambos afetam 
a formação de categorias em slots em construções. Além disso, promovem a produtividade desses slots, bem como seu grau de esquematicidade, permitindo graus variados de analisabilidade dessas construções. Como a representação da variação é parte integrante do sistema da língua, aliar o exame de preferências e restrições associadas a slots de construções, bem como a frequência/produtividade de compatibilização de um (co)lexema em um slot de uma dada construção em relação aos (co)lexemas que se associam a um outro slot diferente da mesma construção pode oferecer evidências empíricas para os estudos sobre variação.

Neste artigo, além de reunirmos conceitos e orientações implicados no tratamento da variação, empreendermos uma discussão teórica de alguns deles, oferecemos ao leitor três exemplos de análise da relação entre (co)lexemas e construção: (i) construção/lexema (pressupondo-se o conceito de categorização baseada na ideia de prototicipicidade); (ii) construção/(co)lexemas (considerando-se algum grau de similaridade entre estes); (iii) construção/ colexema/colocação (esboçando-se a concepção de frequência coercitiva, no sentido de enfatizar a importância da frequência simbólica na categorização da construção).

É preciso dizer que muitos aspectos das ideias apresentadas ainda aguardam uma investigação que os 
aprofunde (inclusive, no que diz respeito a tratamento estatístico), principalmente, no que concerne à análise de (co)lexemas de construções. Acreditamos que o que apresentamos aqui representa uma miscelânea de ideias de trabalho sobre as quais vêm refletindo os que acreditam que a Gramática de Construções pode dar conta da análise da variação. No caso de estudos brasileiros sobre variação em Gramática de Construções, acreditamos que há, ainda, muito o que descortinar. Pensamos, por meio deste artigo, reunir contribuição para passos nesse sentido.

\section{REFERÊNCIAS}

BARDĐDAL, Jóhanna (2008). Productivity: Evidence from Case and Argument Structure in Icelandic. Amsterdam: Benjamins.

BOYD, Jeremy; GOLDBERG, Adele (2011). "E. Learning What Not to Say: The Role of Statistical Preemption and Categorization in $a$-adjective Production". Language 87, 55-83.

BYBEE, Joan (2006). "From usage to grammar: the mind's response to repetition". Language, 82, 711-733.

(2010). Language, usage and cognition. Cambridge, England/ New York, NY: Cambridge University Press.

(2013). "Usage-Based Theory and Exemplar Representations of Constructions". In: HOFFMANN, Thomas; TROUSDALE, Graeme. (Eds.) The Handbook of Construction Grammar. Oxford University Press, p.49-69.

(2015). Language change. Cambridge: Cambridge University Press.

CRISTÓFARO-SILVA, Thaís; GOMES, Christina Abreu (2004). "Representações múltiplas e organização do componente linguístico". Fórum Linguístico, 4(1), 147-177. 
DIESEL, Holger (2015). "Usage-based construction grammar". In: DABROWSKA, Eva; DIVJAK, Dagmar (Eds.), Handbook of Cognitive Linguistics. Berlin: Mouton de Gruyter.

ECKERT, Penelope (2012). "Three waves of variation study: the emergence of meaning in the study of sociolinguistic variation". Annual Review of Anthropology, Palo Alto, 41, 87-100.

FRIED, Mirjam (2015). C"onstruction Grammar". In: A. ALEXIADOU, Alexiadou; KISS, Tibor. (Eds.). Syntax, Theory and Analysis. An International Handbook. Handbooks of Linguistics and Communication Science. 42.1-3, Berlin: Mouton de Gruyter, p.974-1003.

HIMMELMANN, N. P. (2004). "Lexicalization and grammaticization: Opposite or orthogonal?" In: BISANG, Walter; HIMMELMANN, Nikolaus, P.; WIEMER, Björn (Eds.). What makes grammaticalization: A look from its components and its fringes. Berlin: Mouton de Gruyter, p.21-42.

GEERAERTS, Dirk; GRONDELAERS, Stefan; BAKEMA, Peter (1994). The structure of lexical variation: a descriptive framework for cognitive lexicology. Berlin etc.: Mouton de Gruyter.

GOLDBERG, Adele (1995). Constructions: A Construction Grammar approach to argument structure. Chicago: University of Chicago Press.

(2006). Constructions at Work. Oxford: Oxford University Press (2013). Constructionist Approaches. In.: HOFFMANN, Thomas; TROUSDALE, Graeme. (Eds.) The Handbook of Construction Grammar. Oxford University Press, p.15-32.

GRIES, Setfan. Th.; STEFANOWITSCH, Anatol (2004a). "Extending collostructional analysis: A corpus-based perspective on 'alternations'". International Journal of Corpus Linguistics, 9(1), 97-129.

(2004b). "Co-varying collexemes in the into-causative". In: ACHARD, Michel; KEMMER, Suzanne. (Eds.), Language, culture, and mind. Stanford: CSLI, p.225-236.

HILPERT, Martin (2006). "Distinctive Collexeme Analysis and Diachrony". Corpus Linguistics and Linguistic Theory 2/2, p.243-257, 2006. 
(2008). Germanic Future Constructions: A Usage-based Approach to Language Change. Amsterdam: John Benjamins.

(2014). "Collostructional analysis: measuring associations between constructions and lexical elements". In.: GLYNN, Dylan; ROBINSON, Justyna. A. (Eds.), Corpus Methods for Semantics: Quantitative studies in polysemy and synonymy. [Human Cognitive Processing, 43], p.391-404.

LANGACKER, Ronald (1987). Foundations of Cognitive Grammar I: Theoretical Prerequisites. Stanford: Stanford University Press.

LOIOLA, Rubens Lacerda (2018). Construções de aspecto terminativo e cessativo no português brasileiro. (Tese de Doutorado). UFRJ, Faculdade de Letras.

MACHADO VIEIRA, Marcia dos. Santos (2016). "Variação e mudança na descrição construcional: complexo verbo-nominais". Revista Linguística, 152-170.

; WIEDEMER, Marcos Luiz (2018) (No prelo). A variação no modelo construcionista da linguística funcional-cognitiva .

PEREIRA, Bruna Cupello Araripe (2016). A expressão do aspecto de fases no Português: um novo olhar centrado em construções perifrásticas. (Dissertação de Mestrado). UFRJ, Faculdade de Letras.

SCHMID, Hans-Jörg (2016). "A framework for understanding linguistic entrenchment and its psychological foundations in memory and automatization (introduction)". In.: (Ed.). Entrenchment and the Psychology of Language Learning: How We Reorganize and Adapt Linguistic Knowledge (Language and the Human Lifespan Series), Berlim: DE GRUYTER MOUTON, p.9-37.

STEELS, Luc (2013). Fluid Construction Grammar. In: HOFFMANN, Thomas; TROUSDALE, Graeme. (Eds.), The Oxford Handbook of Construction Grammar. Oxford: Oxford University Press, p.133-167.

STEFANOWITSCH, Anatol; GRIES, Stefan (2003). "Collostructions: Investigating the interaction between words and constructions". International Journal of Corpus Linguistics, 8(2), 209-243. 
(2004). "Extending Collostructional Analysis: A Corpus-based Perspective on 'Alternations'". International Journal of Corpus Linguistics 9/1, 97-129.

(2005). "The Function of Metaphor: Developing a Corpus-based Perspective". International Journal of Corpus Linguistics 10/2, 161-198.

(2005). "Covarying collexemes". Corpus Linguistics and Linguistic Theory, 1(1), 1-43.

SUTTLE, Laura; GOLDBERG, Adele (2011). "The partial productivity of Constructions as Induction". Linguistics 49/6, 1237-69.

TRAUGOTT, Elizabeth Closs (1999). "The role of pragmatics in semantic change". In.: VERSCHUEREN, Jef. (Ed.) Pragmatics in 1998: selected papers from the 6th International Pragmatics Conference. Antwerp: International Pragmatics Association, p.93-102.

(2008). "The grammaticalization of NP of NP constructions". In: BERGS, Alexander; DIEWALD, Gabriele (Eds.), Constructions and language change. Berlin: Mouton de Gruyter, p.21-43.

; DASHER, Richard B. (2005). Regularity in semantic change. Cambrigde: Cambridge University Press.

; TROUSDALE, Graeme (2013). Constructionalization and Constructional Changes. Oxford: Oxford University Press.

WIEDEMER, Marcos Luiz (2013). Variação e gramaticalização no uso de preposições em contextos de verbos de movimento no português brasileiro. (Tese - Doutorado em Linguística) - Programa de Pós-graduação em Estudos Linguísticos do Instituto de Biociências, Letras e Ciências Exatas, Universidade Estadual Paulista, São José do Rio Preto.

(2014) "Para uma visão conceptual das preposições que complementam verbos de movimento no português brasileiro". Veredas, 102-122.

; MACHADO VIEIRA, Marcia dos Santos (2018) (No prelo). In.: FRANCESCHINI, Lucelene Teresinha; LOREGIAN-PENKAL, Loremi (Orgs.) Sociolinguística: estudos de variação, mudança e atitudes linguísticas. Guarapuava: UNICENTRO. 
WINTERS, Margaret (1992) "Schemas and prototypes: remarks on syntax change". In.: KELLERMANN, Günter; MORRISSOY, Michael (Eds). Diachrony within Synchrony: Language History and Cognition. Frankfurt/Berlim: Peter Lang, p.265-280.

WULF, S.; STEGANOWITSCH, Anatol; GRIES, Stefan.Th. (2007). "Brutal Brits and persuasive Americans: Variety-specific meaning construction in the into-causative." In.: RADDEN, Günter; KÖPCKE; Klaus-Michael; BERG, Thomas; SIEMUND, Peter. (Eds.). Aspects of meaning construction. Amsterdam: John Benjamins, p.265-281.

Marcos Luiz Wiedemer é Professor do Programa de Pós-graduação em Letras e Linguística (PPLIN), Universidade do Estado do Rio de Janeiro (UERJ) / Faculdade de Formação de Professores (FFP). Membro (pesquisador) do Grupo de Pesquisa "Discurso \& Gramática" (UFF) e membro (efetivo) do Grupo de Trabalho "Sociolinguística" da ANPOLL. Atualmente, é Coordenador Geral do PPLIN (gestão 2018-2020). E-mail: mlwiedemer@gmail.com

Marcia dos Santos Machado Vieira é Professora do Programa de Pósgraduação em Letras Vernáculas, Universidade Federal do Rio de Janeiro (UFRJ) / Faculdade de Letras. Membro (pesquisador) do Grupo de Pesquisa "Discurso \& Gramática" (UFRJ) e membro (efetivo) do Grupo de Trabalho "Sociolinguística" da ANPOLL. E-mail: marcia@letras.ufrj.br. 